\title{
WHAT? NOT ANOTHER PICTURE BINGO GAME!
}

\section{Antoinette Gagné}

Yes, it's another picture bingo game! However, in this version of picture bingo, an attempt has been made to simplify the preparation and duplication of the game. In addition, there is an increase in the complexity of linguistic items practised throughout the game as compared to other types of bingo games.

The picture bingo described here is suitable for beginner level ESL learners of any age. Children, adolescents and adults generally enjoy participating in this type of activity. First, the preparation of the master bingo card will be described and then the game rules will be explained.

The first step is to prepare the master bingo card. If you are not afraid of doing a bit of drawing, just put your fingers to work and draw your own master bingo card. Remember that it is not necessary to produce a masterpiece. On the other hand, if you are as insecure about your drawing talents as I am, at this point you will need a sheet of paper, a pencil, an adhesive and a series of thematically organized pictures. Only small pictures are suitable for the preparation of the master bingo card. Two good sources for such pictures are The Basic Vocabulary Builder and The Practical Vocabulary Builder, both published by The National Textbook Company in the form of reproducible stencil books. If these books are not available, small yet clear illustrations can be found in catalogues, flyers, the yellow pages of the telephone directory and in inexpensive picture dictionaries produced for children.

Using whatever is available, assemble as many thematically related pictures as will fit on an average sized sheet of paper. Then, distribute them evenly, paste them down and number each illustration clearly (see the sample master bingo cards in the appendix).

The next step involves drawing a series of game grids below your randomly sequenced illustrations. Game grids can take a variety of forms as long as sufficient space for writing a series of numbers is provided (see the sample game grids in the appendix).

The next task is to prepare 3 lists of statements of increasing difficulty for use during the game. The following lists accompany the "Leisure Time Activities" master bingo card:

\section{List 1}

She's watching TV.

He's playing baseball.

They're dancing rock n' roll.

She's skiing

She's taking pictures. 
They're playing cards.

She's playing tennis.

Somebody is playing chess.....

\section{List 2}

Penny is watching TV in the living room.

Brad is playing baseball with the Expos.

Trish and Dan are dancing together at the annual school party.

Lisa is skiing down Mont Tremblant.

Sally is trying to take a good picture of a squirrel.

Every Wednesday night the Parkers play cards with Bob.

Laura plays tennis every day during the summer.

Many people enjoy playing chess....

\section{List 3}

Some people are addicted to watching TV.

Sports experts say that batting is easier than pitching.

It is rare to have a live rock band at a party.

There is a lot of excitement involved in downhill skiing.

More and more people are involved in photography as a hobby.

Bridge is a popular card game.

If you are a professional, you can actually win a lot of money playing tennis.

A young Canadian recently invented a tridimensional form of chess that he calls "Triman"....

Once you have prepared the master game card with illustrations, game grids and accompanying lists, it is time to get your students involved in a round of bingo. In order to do this give each student a copy of the master game card and have them complete game grid 1. Explain that only one game grid is used for each round of picture bingo. In order to complete the first grid, each student must fill in all the spaces using a random selection of numbers between 1 and 20 and without repeating the same number twice. Point out that each number corresponds to an illustration on the game card and that each student should end up with a different game grid.

Next, determine what is required in order to be a winner. For example, when using game grid 1 , you may specify that 4 squares going in any direction merit a bingo; or, when using game grid 3 you may decide that all the triangles and rectangles are needed to win; or, last of all, when using game grid 4, you may specify that a full face is needed to win.

By designing a variety of game grids, you can provide extra practice or review of items introduced earlier in the course. For example, to review the parts of the body, shapes, sizes and comparatives you could draw game grids on your master bingo card similar to the ones illustrated in the samples in the appendix. 
Once all of your students have prepared their first game grid, you can begin calling items from any one of the lists that you prepared earlier. It is a good idea to call out simple statements at first when the students are not familiar with the rules of the game and to use more difficult statements only when the students are more comfortable with the working of the game. For example you could begin calling: "He's swimming." and later move on to calling "The Canadian Athletes did very well in the swimming competitions at the 1984 Olympics."

Once you have called out a statement, your students must locate the picture on the master bingo card which corresponds most closely to what has been said. In the example above, the corresponding illustration is \#12. The next step is for all of your students to check their grids and cross off $\# 12$ if it appears anywhere.

You or a designated student should then continue to call items from the lists until there is a winner, i.e., until one student has crossed out the winning combination of spaces on his/her grid. The game can then be put away for use at a later date or game grid 2 can be used to play another round on the same day.

When using the same master game card for a third or fourth time, it is important to increase the level of difficulty of the statements called as well as the criteria for winning in order to ensure that your students remain motivated.

Using this type of bingo activity at the beginner level is very beneficial for ESL learners because it provides for a great deal of meaningful listening practice which is essential for the development of communicative competence. In addition, this game format makes it possible to practice and review a wide variety of linguistic items. Master game cards can easily be prepared for use with any thematic teaching unit such as food, clothing or means of transportation. Finally, it is easy to prepare and it will provide a refreshing change of pace to the routine in the ESL class.

\section{FOOTNOTE}

All the illustrations used for the preparation of the master bingo cards were taken from The Basic Vocabulary Builder and The Practical Vocabulary Builder published by The National Textbook Company.

\section{THE AUTHOR}

Antoinette Gagné is a professor at McGill University in the Department of Education in Second Languages. She has given numerous workshops on ESL methodology, particularly games, songs and communicative activities in the ESL classroom. 


\section{APPENDIX A}

\section{MASTER BINGO CARDS AND GAME GRIDS}

Leisure Time Activities
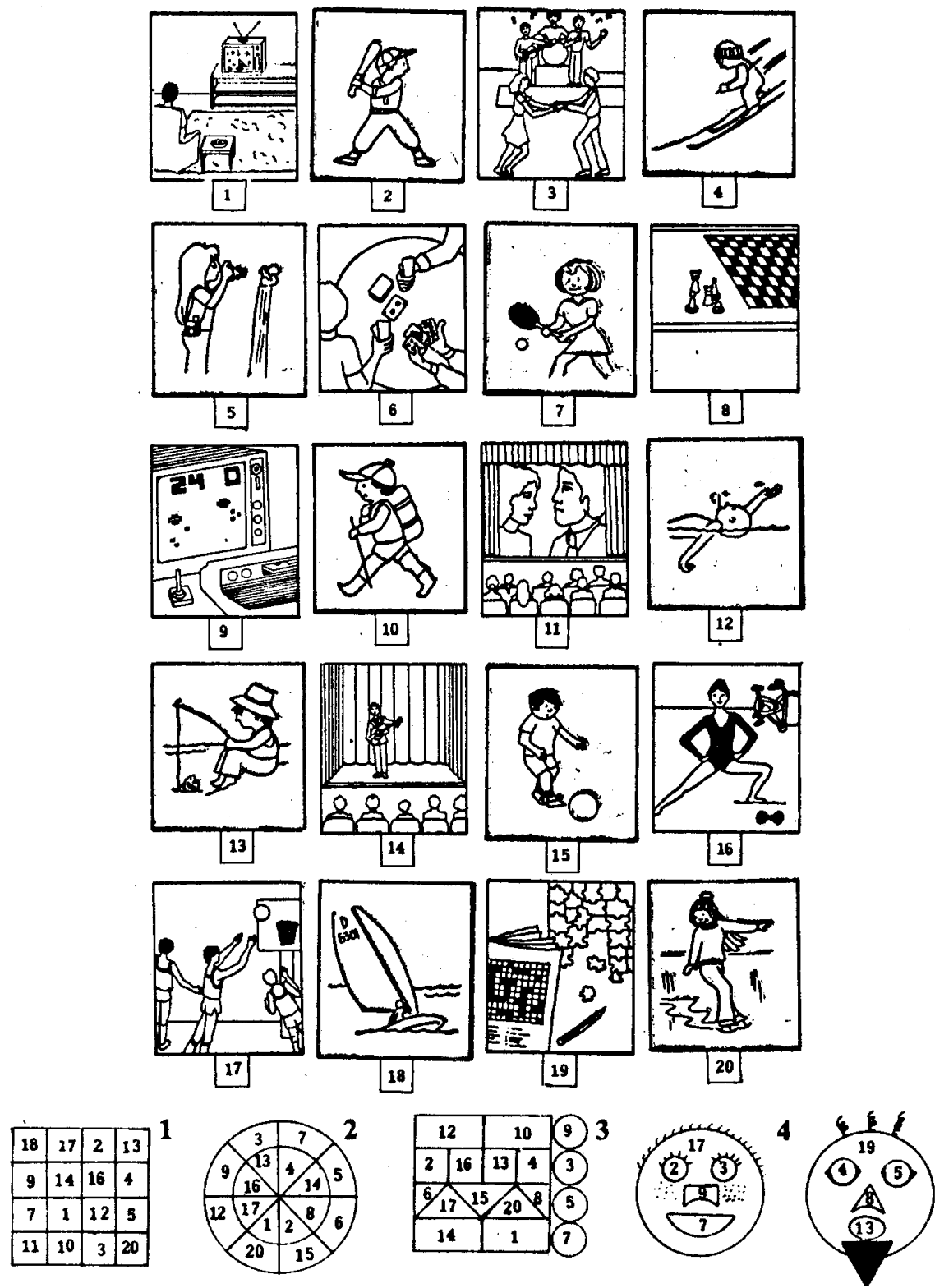
Occupations and Professions
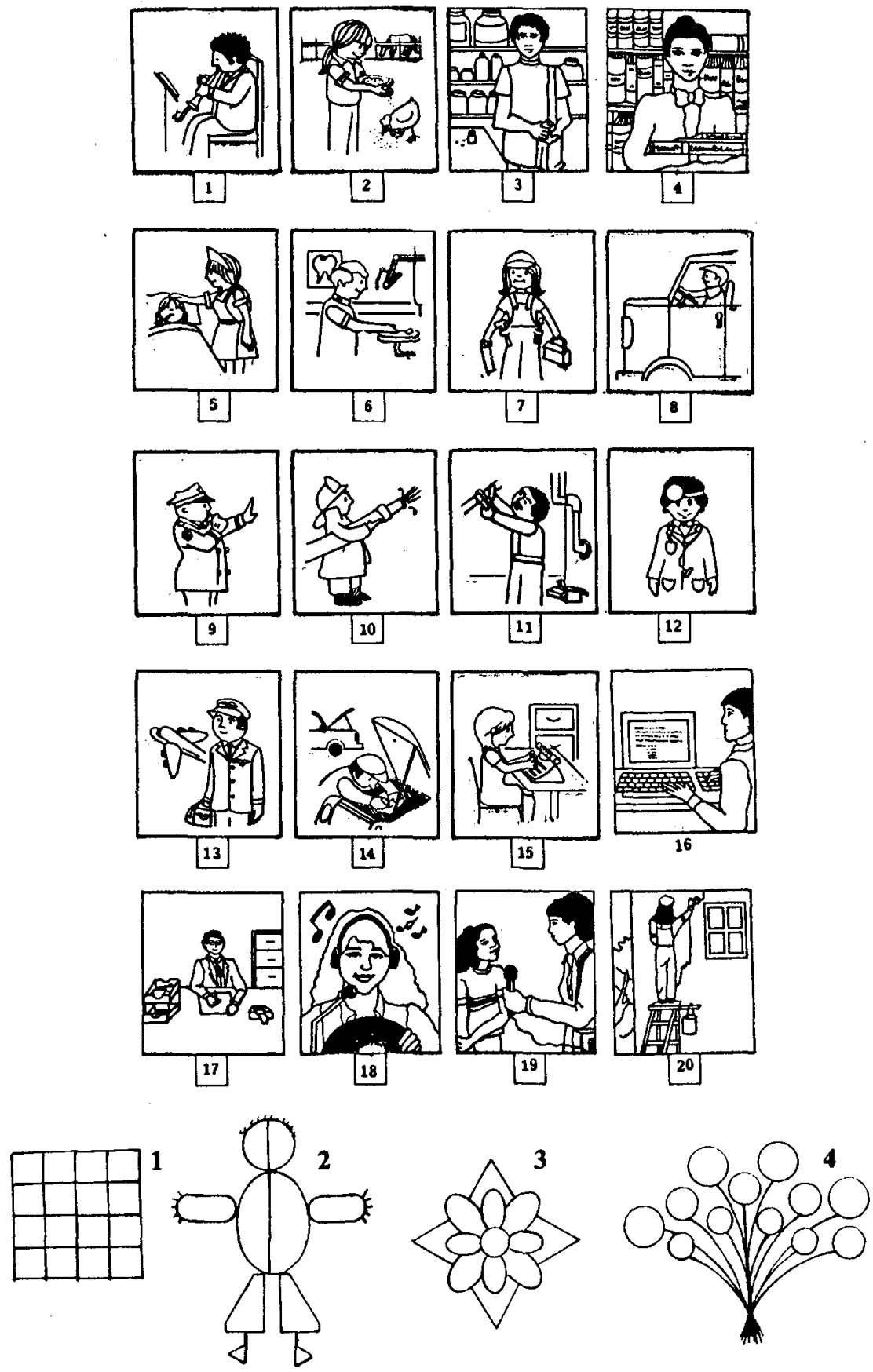